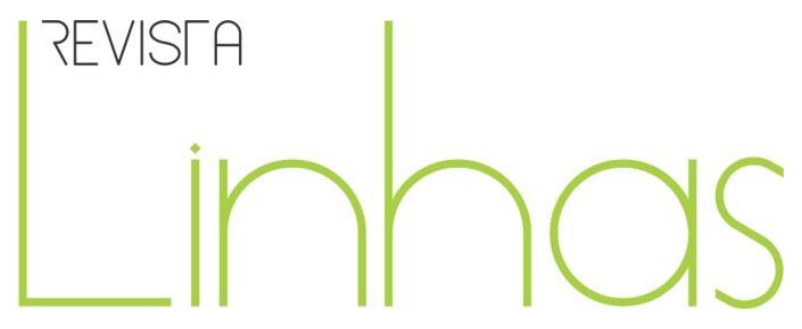

\title{
Educação Superior nas dissertações e teses brasileiras: a aprendizagem significativa como perspectiva de análise
}

\begin{abstract}
Resumo
O presente artigo descreve o estudo que buscou compreender a opção de autores de teses e dissertações, publicadas em âmbito nacional, pela Teoria da Aprendizagem Significativa (AUSUBEL, 1982, 2006) no contexto da Educação Superior. Tendo em vista responder à questão sobre qual a justificativa dos autores das teses e dissertações selecionadas da opção pela Teoria da Aprendizagem de Ausubel na Educação Superior, selecionaram-se três categorias de análise, quais sejam: justificativa dos autores analisados da opção pela teoria de Ausubel, situação da aplicação da teoria e resultados/conclusões. $\mathrm{Na}$ consideração dessas categorias, constatou-se que a maioria dos autores investigados optou pela Teoria da Aprendizagem Significativa por centrar-se na importância do conhecimento prévio para a aprendizagem, tendo se utilizado dela como fundamento didático para potencializar a aprendizagem significativa dos alunos. Além disso, os autores concluíram que o envolvimento coletivo colaborativo dos acadêmicos participantes do processo de ensino e a utilização de procedimentos metodológicos, com destaque aos mapas conceituais, tendem a promover a aprendizagem significativa.
\end{abstract}

Palavras-chave: Aprendizagem. Ausubel, David Paul. Educação Superior.

\author{
Vera Lúcia Leal Crispim \\ Conselho Regional de Psicologia - \\ SC - Brasil \\ veral.crispim@hotmail.com
}

\section{Antonio Serafim Pereira}

Universidade do Extremo Sul

Catarinense - Unesc - Criciúma/SC Brasil asp@unesc.net

\footnotetext{
Para citar este artigo:

CRISPIM, Vera Lúcia Leal; PEREIRA, Antonio Serafim. Educação Superior nas dissertações e teses brasileiras: a aprendizagem significativa como perspectiva de análise. Revista Linhas. Florianópolis, v. 21, n. 46, p. 224251, maio/ago. 2020.
} 


\title{
Higher Education in brazilian dissertations and theses: significant learning as an analysis perspective
}

\begin{abstract}
This article describes the study that seeks to understand the choice of authors of theses and dissertations published in the national context by the Theory of Significant Learning (AUSUBEL, 1982, 2006), in the context of Higher Education. In order to answer the question about the justification of the authors of the theses and dissertations selected from the option for the Ausubel Theory of Learning in Higher Education, three categories of analysis were selected: justification of the authors analyzed of the option for the theory of Ausubel, situation of application of theory, results / conclusions. In the consideration of these categories, it was verified that the majority of the authors analyzed chose the Theory of Significant Learning to focus on the pertinence / importance of previous knowledge for meaningful learning, and it was used as a didactic foundation to enhance students' learning. In addition, the authors conclude that the collaborative collective involvement of the academic participants in the teaching process and the use of methodological procedures, with emphasis on conceptual maps, tend to promote meaningful learning.
\end{abstract}

Keywords: Learning. Ausubel, David Paul. Higher Education. 
O presente trabalho ${ }^{1}$ versa sobre a Teoria da Aprendizagem Significativa na Educação Superior. A opção por essa abordagem, decorrente de nossa experiência como docentes nesse nível de ensino, tem-nos possibilitado perceber - considerando o perfil dos acadêmicos, muitos deles inseridos no mercado de trabalho, entre outras experiências sociais e educacionais - que, de uma forma ou de outra, estes já possuem noções prévias sobre os conhecimentos abordados, o que nos instiga a pensar sobre a prática docente que desenvolvemos e o potencial contributivo das teorias de aprendizagem, em particular, da perspectiva teórica mencionada, para redimensioná-la.

Para nos certificarmos da viabilidade do estudo, inicialmente realizamos levantamento bibliográfico no Banco de Teses da Coordenação de Aperfeiçoamento de Pessoal de Ensino Superior (CAPES) e também na Biblioteca Digital Brasileira de Teses e Dissertações (BDTD) sobre os trabalhos produzidos no período de 2001 a 2014 concernentes à temática.

Ao concluirmos o processo de busca e seleção das teses e dissertações produzidas no período citado, o encaminhamento subsequente foi definir as categorias de análise e realizar a leitura dos trabalhos que nos permitiram responder ao problema do estudo realizado: qual a justificativa dos autores das teses e dissertações selecionadas para análise da opção pela Teoria da Aprendizagem de Ausubel na Educação Superior? Tal pergunta nos remeteu à formulação do objetivo geral da pesquisa, que ficou assim configurado: compreender a razão da opção teórica dos autores dessas produções pela Aprendizagem Significativa aplicada à Educação Superior, o que resultou no desdobramento dos seguintes objetivos específicos:

a) Conhecer as principais teorias que incidem sobre a aprendizagem, articuladas com materiais produzidos já consolidados pelos meios e pelas práticas acadêmicas.

b) Identificar o contexto da Educação Superior no qual o estudo dos autores das dissertações e teses foi desenvolvido.

c) Analisar a relação entre a metodologia e a opção teórica desenvolvida pelos autores das teses e dissertações analisadas.

\footnotetext{
${ }^{1}$ Constituído a partir da dissertação (Mestrado em Educação) de um dos autores.
} 
d) Analisar os resultados/as conclusões apresentados nas dissertações e teses no que se refere à Aprendizagem Significativa na Educação Superior.

A relevância do estudo empreendido, considerando o atual contexto educacional, justifica-se pela importância de o professor da Educação Superior se apropriar do conhecimento a respeito das teorias de aprendizagem, um saber pedagógico que busca aproximar os entendimentos educacionais da atualidade alinhando-os com a formação do professor e dos alunos, bem como de uma aprendizagem realmente significativa e suas diferentes concepções. Além disso, pela importância de desenvolver uma discussão conceitual e argumentativa a respeito da Aprendizagem Significativa e demais concepções de aprendizagem que lhes proporcionem evidenciar novos conhecimentos a serem construídos por meio delas.

Desse modo, é possível rever e refletir sobre o modelo de educação que se está oferecendo aos alunos da Educação Superior, que características se buscam nos docentes para que possam potencializar, de maneira mais concreta, as propostas curriculares dos cursos em que atuam a partir do conhecimento e interpretação das principais teorias da aprendizagem, em particular da teoria de Ausubel.

Nesse intento, tecemos considerações sobre a Teoria da Aprendizagem Significativa ancoradas em seu próprio idealizador, apoiadores, colaboradores e críticos, situando-as no cenário das Diretrizes Curriculares Nacionais dos cursos superiores, que serviram de campo para as pesquisas aqui analisadas (graduação em Matemática e Física). Além disso, analisamos a relação entre a justificativa da opção pela Teoria da Aprendizagem Significativa e a metodologia da pesquisa empreendida pelos autores das dissertações e teses.

\section{Teoria da Aprendizagem Significativa de Ausubel}

A Teoria da Aprendizagem Significativa integra a concepção cognitiva das teorias de aprendizagem, haja vista sua defesa de que a aprendizagem ocorre a partir da organização e consequente integração de informações na estrutura cognitiva do aprendiz. Contrapõe-se, portanto, segundo Ausubel (1982), à aprendizagem mecânica 
decorrente da memorização de informações, sem correlação com os conteúdos assimilados e internalizados pelo aluno.

Analisando a Teoria da Aprendizagem Significativa, Pérez Gómez (1998) certificouse de que a aprendizagem, nesta perspectiva, deve atender a aspectos lógicos e psicológicos que acontecem significativamente quando o processo está vinculado à bagagem de conceitos ou ideias condizentes com a estrutura cognitiva do aprendiz. Isto é, a aprendizagem verdadeiramente significativa pressupõe a reorganização cognitiva e atividade interna do aprendente. Studer e Casagrande (1999), nesse mesmo sentido, apontam que a aprendizagem significativa se manifesta de modo abrangente no contexto da Educação Superior, uma vez que os aprendizes inseridos nesse nível educacional fazem uso constante dos conhecimentos presentes e organizados em suas respectivas estruturas cognitivas, relacionando-os com as novas informações obtidas.

Por esse ângulo, quando o aluno detém uma estrutura cognitiva, devida e logicamente organizada, torna-se mais apto para fazer uso do conhecimento internalizado, objetivando a aquisição de novos conhecimentos e aprendizagens, o que se torna possível diante da interação do aprendiz com a realidade que o cerca. Para Ausubel (1982), o aluno precisa manifestar disposição prévia para relacionar, intencionalmente, o novo conhecimento a ser aprendido com o respaldo dos conhecimentos e informações presentes em sua estrutura cognitiva. Moreira (1999) defende que, no âmbito da Educação Superior, as estratégias pedagógicas concebidas pela Teoria da Aprendizagem Significativa precisam contemplar a articulação dos chamados conceitos obrigatórios com os saberes prévios presentes e organizados na estrutura cognitiva dos acadêmicos, garantindo-lhes protagonismo no processo de apropriação ativa dos conhecimentos e informações a eles apresentados. Para o autor, as instituições de Educação Superior devem favorecer o desenvolvimento das capacidades intelectuais, habilidades humanas e também profissionais dos alunos, valendo-se da aprendizagem significativa para que os acadêmicos possam se desenvolver a partir de suas ideias, raciocínios, sentimentos, culturas, profissões, do meio social e intelectual no qual transitam.

Para Valadares e Moreira (2009), a distinção primordial entre os processos de aprendizagem por memorização e a aprendizagem significativa deve-se ao fato de que, na primeira, a aprendizagem de novas informações se dá sem conexão com elementos 
existentes na estrutura cognitiva do aprendente, enquanto na segunda é prevalente a interação entre novos conteúdos potencialmente significativos e ideias relevantes existentes e organizadas na estrutura cognitiva do aprendiz.

A teoria de Ausubel salienta que a interação entre novas informações e conhecimentos prévios dos aprendizes pressupõe que conceitos subsunçores sejam constituídos, visando à potencialização da aprendizagem. O autor considera que o que determina a atividade ou técnica proposta pelo docente no âmbito do processo de ensino-aprendizagem é a perspectiva de que o aluno relacione novas informações, de modo não arbitral e não literal, com saberes já incorporados à sua estrutura cognitiva (AUSUBEL, 2006).

Tendo em vista que o aluno é o sujeito central a ser considerado no processo de aprendizagem significativa, Ausubel (2006) defende que um novo conhecimento pode ser adquirido e assimilado de modo ideal, quando conceitos proeminentes e inclusivos estejam disponíveis na estrutura cognitiva do aprendiz, a partir de registros e ideias individuais, permitindo-lhe formar uma nova categoria conceitual.

Vale relevar, para a devida compreensão da teoria, o que são os subsunçores aos quais Ausubel (2006) se refere. Valadares e Moreira (2009) argumentam que os subsunçores podem ser conceituados como os conhecimentos prévios existentes na estrutura cognitiva do aluno. No mesmo sentido, Ausubel, Novak e Hanesian (1980) sustentam que o papel desempenhado pelos subsunçores se concretiza quando o conteúdo a ser aprendido consegue se relacionar a algo já conhecido. Quando tal papel não se objetiva, a aprendizagem acaba se efetivando de modo mecânico, uma vez que as novas informações não interagem com conhecimentos e conceitos existentes/relevantes na estrutura cognitiva do aprendente.

Para Pelizzari et al. (2001), no contexto da aprendizagem significativa, o aprendiz deve produzir um significado otimizado de novas informações apoiado na relação com o conhecimento que ele detém. Quando não há tal conexão, não se fala em aprendizagem significativa, mas em aprendizagem mecânica ou repetitiva, posto que informações podem ser armazenadas de modo isolado ou mediante associações arbitrárias na estrutura cognitiva do aprendiz. 
Nessa circunstância, Ausubel (2006) defende que a ocorrência da aprendizagem significativa depende da mudança no modo pelo qual o conhecimento é concebido sob a perspectiva dos processos cognitivos. Para tanto, é indispensável que o docente reflita sobre a conexão entre o novo conteúdo proposto e o conteúdo existente na hierarquia cognitiva do aluno. Logo, não há como se falar em aprendizagem significativa quando o aprendiz se depara com um campo de conhecimento totalmente novo. Essa compreensão pode ser verificada sempre que se apresenta um conteúdo novo ao aluno. Quando o estudante é apresentado pela primeira vez aos conhecimentos matemáticos, por exemplo, ele se depara com um contexto de aprendizagem que não pode ser produzido de maneira significativa, mas mecanicamente, uma vez que, via de regra, não detém, em sua estrutura cognitiva, conhecimento relevante nessa área.

Assim sendo, tem-se que os organizadores do conhecimento prévio compõem "uma parte cognitiva que permitiria a pronta ligação entre os subsunçores relevantes e o novo material a ser aprendido." (AUSUBEL, 2006, p. 60). Por isso a disposição do aluno para o processo de aprendizado é tão substancial quanto a significação da aprendizagem de um novo conhecimento ou informação. Nesse sentido, reveste-se de importância a orientação do docente com vistas a promover a disposição dos alunos para aprender significativamente a partir da interação entre os conhecimentos e a aplicação da aprendizagem de modo significativo.

Conforme Moreira (2012), a aprendizagem significativa pode se configurar de três formas primordiais: por subordinação, por superordenação e de modo combinatório.

$\mathrm{Na}$ forma subordinada, os novos conhecimentos (potencialmente significativos) adquirem significados para o sujeito, o qual aprende por um processo de ancoragem cognitiva e interativa em conhecimentos prévios relevantes mais gerais e inclusivos em sua estrutura cognitiva (MOREIRA, 2012).

A aprendizagem na forma superordenada ocorre quando um conceito ou uma nova proposição é relacionado a proposições já existentes na estrutura cognitiva do aprendente, envolvendo processos de indução e síntese, gerando novos conhecimentos que se subordinam aos que lhe deram origem (KLEINKE, 2003). 
$\mathrm{Na}$ forma combinatória, a aprendizagem significativa advém de novas proposições, as quais não apresentam relação subordinada, nem superordenada com ideias relevantes adquiridas anteriormente na estrutura cognitiva do aprendiz, visto que a ideia nova e as ideias já estabelecidas não se relacionam hierarquicamente, mas se encontram no mesmo nível, não sendo mais específicas ou inclusivas do que outras ideias (PIVATTO; SCHUHMACHER, 2013).

Fala-se ainda em uma aprendizagem significativa representacional, que se relaciona às representações, além de uma aprendizagem significativa conceitual (referente a conceitos) e uma aprendizagem significativa proposicional (referente a proposições). No entender de Ausubel (2006), a aprendizagem representacional é o tipo mais básico de aprendizagem significativa, envolvendo a atribuição de significados aos símbolos, com base na identificação. Assim, determinada palavra (ou qualquer outro símbolo) representa um significado baseado em representações. A aprendizagem representacional envolve a atribuição de significados a símbolos arbitrários, os quais podem ser identificados com seus referentes e passam a significar para o indivíduo aquilo que seus referentes significam.

A aprendizagem conceitual, segundo o autor, assemelha-se à representacional, uma vez que os conceitos também são representados por símbolos específicos, de modo abstrato dos atributos essenciais de seus referentes, em virtude de que os símbolos possuem atributos comuns, designados de acordo com o símbolo aceito.

$\mathrm{Na}$ aprendizagem proposicional, o intuito não é 'aprender significativamente' o que palavras isoladas ou combinadas representam, mas o significado de ideias na forma de proposição. Tais palavras, combinadas em uma sentença, compõem uma proposição representativa dos conceitos, de maneira que o significado das ideias é expresso verbalmente por meio de tais conceitos, sob a forma de proposição. Enfim, a aprendizagem proposicional refere-se à compreensão do significado para além da soma dos significados e dos símbolos e conceitos incorporados à proposição.

Esses são os elementos fundamentais que podem nos conduzir a um melhor entendimento da Teoria da Aprendizagem Significativa, e que estão sintetizados, de certa maneira, na recomendação - uma das mais recentes - de Moreira: 
No processo de aprendizagem significativa, na captação e internalização de significados, deve haver uma interação cognitiva entre conhecimentos novos e conhecimentos prévios. [...] Nessa interação o novo conhecimento ganha significados e o conhecimento prévio pode ficar mais estável, mais diferenciado, com novos significados, e pode servir de ancoradouro cognitivo para novas aprendizagens. (MOREIRA, 2015, p. 5)

Tais elementos, por certo, inspiraram Novak (1981) a desenvolver, no ano de 1972, os mapas conceituais, que passaram a ser considerados como estratégias mobilizadoras da aprendizagem significativa a partir do mapeamento de conceitos que descrevem objetos, eventos ou situações com características comuns. Segundo o autor, os mapas conceituais estabelecem as relações entre conceitos, estruturando suas conexões e demonstrando as associações existentes entre eles. Tais mapas são utilizados para representar, construir e avaliar conhecimentos.

Conforme Moreira (2012), os mapas conceituais obedecem aos princípios de diferenciação progressiva e reconciliação integrativa da aprendizagem significativa, organizados respeitando a hierarquia dos conceitos, para que seja possível realizar ligações entre eles. Nas palavras do autor,

[...] mapas conceituais não buscam classificar conceitos, mas relacionálos e hierarquizá-los, sendo possível traçá-los [...] para uma única aula, para uma unidade de estudo, para um curso ou, até mesmo, para um programa educacional completo. A diferença está no grau de generalidade e inclusividade dos conceitos dispostos no mapa. Um mapa envolvendo apenas conceito geral, inclusivo e organizacional pode ser usado como referencial para o planejamento de um curso inteiro, enquanto um mapa incluindo somente conceitos específicos, pouco inclusivos, pode auxiliar na seleção de determinados materiais instrucionais. (MOREIRA, 2012, p. 2)

Inúmeras possibilidades no uso de mapas conceituais são apontadas por seus defensores como estratégia de ensino. Entre as mais comuns, citamos: modo de explorar o que os alunos já sabem (conhecimento prévio); síntese de informações; estratégia de autoaprendizagem; meio de avaliação; preparação de trabalhos escritos e/ou orais; compreensão de livros e/ou textos. Acreditamos que tais possibilidades têm se constituído em fortes razões para a disseminação/relevância dos mapas conceituais no âmbito dos estudos que envolvem a Teoria da Aprendizagem Significativa de Ausubel. 


\subsection{Aprendizagem Significativa: fortuna crítica}

Discutimos, neste tópico, questões básicas da Teoria da Aprendizagem Significativa de Ausubel sob o ponto de vista de seus críticos, dentre os quais Cachapuz (2000), Galagovsky (2004) e Moreira (2010, 2012).

Para Moreira (2012) tão somente o conhecimento prévio não se mostra suficiente para lidar com a aprendizagem significativa. Desse modo, termos presente que os significados dos fatos e situações vivenciados e compartilhados são idiossincráticos, assume relevância substancial, pois demandará a busca de novas estratégias para descobrir caminhos que nos levem ao encontro das necessidades proeminentes que surgem com muita rapidez nos meios educacionais, principalmente na Educação Superior. Nessa direção, o autor indica alguns princípios recomendáveis na prática do ensino:

Perguntas ao invés de respostas (estimular o questionamento ao invés de dar respostas prontas). Diversidade de materiais (abandono do manual único). Aprendizagem pelo erro (é normal errar; aprende-se corrigindo os erros). Aluno como preceptor representador (o aluno representa tudo o que percebe). Consciência semântica (o significado está nas pessoas, não nas palavras). Incerteza do conhecimento (o conhecimento humano é incerto, evolutivo). Desaprendizagem (às vezes o conhecimento prévio funciona como obstáculo epistemológico). Conhecimento como linguagem (tudo o que chamamos de conhecimento é linguagem). Diversidade de estratégias (abandono do quadro de giz). (MOREIRA, 2010, p. 13)

Machado (2015) reconhece, como tantos outros autores, o mérito de Ausubel como intelectual fundante da Aprendizagem Significativa, mas atribui a seus colaboradores, entre eles Moreira, a articulação mais intensa dos seus princípios teóricos ao espaço da sala de aula, ao considerar o discente na conjunção inter-relacional do pensar, sentir e agir a partir de uma abordagem crítica. A teoria de Ausubel (1982), nesse sentido, não engloba o processo de aprendizagem na sua complexidade, uma vez que, segundo Cachapuz (2000), uma de suas limitações está na sobrevalorização dos saberes conceituais e diz respeito à ausência de interligação aos demais aspectos ou dimensões que compõem a complexidade da aprendizagem: biológica, cognitiva, social e do sujeito. Outra limitação identificada pelo autor consiste na controvérsia sobre a organização 
hierárquica dos conceitos, dos mais inclusivos para os menos inclusivos na mente do aluno. Vejamos:

Há fundamentadas razões para pensar que não só a organização psicológica não tem necessariamente que seguir um tal padrão lógico (sobretudo nos alunos mais jovens) mas que tal organização hierárquica é provavelmente mascarada por constrangimentos relativos às próprias instruções dadas aos alunos para a construção dos designados mapas de conceitos bem como pelos exemplos geralmente propostos (domínios altamente estruturados). Tal não significa não reconhecer o interesse [didático] de tais instrumentos, mas tão só alertar para a confusão que frequentemente se estabelece entre o construto e a sua representação acessível. (CACHAPUZ, 2000, p. 68-69)

Galagovsky (2004), por sua vez, organizou um modelo teórico próprio sobre a aprendizagem assentado em suas reflexões sobre a teoria de Ausubel, designado de aprendizagem sustentável, dando destaque à aquisição de conceitos, mas minimizando a centralidade da influência do desenvolvimento de operações cognitivas do aluno mediante o resgate do papel do professor como provedor dos conhecimentos no processo de aprendizagem significativa por parte daquele.

A referida proposta de aprendizagem contrapõe-se à ideia de Novak (1981), para quem um discurso docente bem organizado garante a aprendizagem significativa. Conforme a autora, a diversidade dos estudantes não será contemplada na sua totalidade por todas as pontes cognitivas formuladas a partir do discurso docente, posto que a elaboração/apropriação do conhecimento é idiossincrática. Em seu ponto de vista, é necessário

[...] reconsiderar o lugar que ocupa o discurso docente a respeito dos processos mentais requeridos para sua apropriação por parte do sujeito cognoscente $[\mathrm{e}]$ reconsiderar o conceito de aprendizagem significativa tanto desde sua origem na teoria da assimilação da aprendizagem como desde o significado prático que adquiriu no mundo educativo real. (GALAGOVSKY, 2004, p. 231, tradução nossa)

Nos termos de Galagovsky (2004), a aprendizagem sustentável ocorre com o aumento da rede de conhecimentos prévios a partir da apropriação da informação recebida (ou parte dela) como novo conhecimento. Trata-se de nova construção que é, ao mesmo tempo, uma reconstrução da estrutura cognitiva pré-existente. Tal 
reconstrução, segundo a autora, ocorre por meio da ressignificação dos conceitos de apoio que serviram de nexo para a incorporação do novo conhecimento. Admite a possibilidade de ocorrer um tipo de aprendizagem decorrente de mecanismos de memória de longo prazo do indivíduo que acontece quando o sujeito não interliga informações com conhecimentos prévios. É a aprendizagem isolada, que se opõe à aprendizagem sustentável.

Tendo em vista o exposto, apresentamos, à guisa de síntese, no Quadro 1, os aspectos básicos da crítica de Cachapuz (2000), Galagovsky (2004) e Moreira (2010, 2012).

Quadro 1: Crítica à Teoria da Aprendizagem Significativa: aspectos básicos

\begin{tabular}{|c|c|c|c|}
\hline \multirow{3}{*}{$\begin{array}{c} \\
\text { Crítica: } \\
\text { aspectos } \\
\text { básicos }\end{array}$} & \multicolumn{3}{|c|}{ Autores } \\
\hline & Cachapuz (2000) & Galagovsky (2004) & Moreira $(2010,2012)$ \\
\hline & 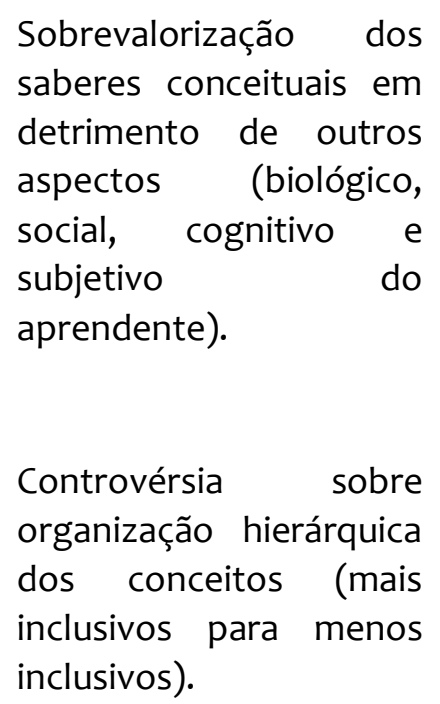 & 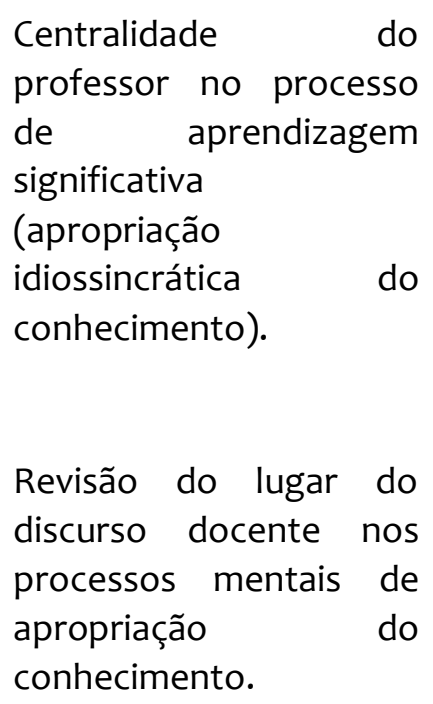 & $\begin{array}{l}\text { Conhecimento prévio } \\
\text { não suficiente para } \\
\text { aprendizagem } \\
\text { significativa } \\
\text { (significados são } \\
\text { idiossincráticos). } \\
\begin{array}{l}\text { Conhecimento prévio } \\
\text { pode funcionar como } \\
\text { obstáculo } \\
\text { epistemológico. }\end{array}\end{array}$ \\
\hline
\end{tabular}

Fonte: elaboração dos autores (2018).

A crítica de Moreira (2010), as limitações destacadas por Cachapuz (2000) e Galagovsky (2004), dentre outras posições, têm contribuído para problematizar o encaminhamento teórico de Ausubel $(1982,2006)$ e Novak (1981). Ao mesmo tempo, têm instigado o desenvolvimento de novas pesquisas e propostas pedagógicas no campo da aprendizagem. Ou seja, ao considerar que o conhecimento prévio e o novo conhecimento (e a própria estrutura cognitiva) em interação se modificam e não voltam ao seu estado 
inicial, Ausubel (1982) abre demanda para linhas de pesquisa sobre como ocorre e quais os resultados dos conhecimentos modificados por esse processo.

De todo modo, a par das limitações teóricas postas em evidência e as que se poderão apontar no futuro a respeito da Aprendizagem Significativa, é preciso, pois, reconhecer suas contribuições. Uma delas está no fato de que, em relação ao ensino, é essencial considerar que as representações que o estudante faz do seu cotidiano ou do conhecimento tido como funcional colocam-no como agente no processo de aprendizagem; ele deixa de ser mero receptor de informações e passa a ser sujeito capaz de perceber e representar o mundo ao seu redor.

Para além da dependência das concepções do professor, a natureza problematizadora da abordagem dos conteúdos escolares e o confronto direto das ideias dos estudantes podem, consequentemente, levar à aprendizagem significativa. Dessa maneira, tal abordagem pode constituir-se em possibilidade para a formação do cidadão capaz de transformar o meio em que vive de forma consciente, contrapondo-se à memorização e à mera reprodução do conteúdo escolar, que têm servido para fortalecer a reprodução e perpetuação das estruturas sociais que legitimam a desigualdade e as injustiças.

A seguir, apresentamos a metodologia da pesquisa realizada, a análise e discussão dos resultados obtidos, incluindo as considerações finais. Antes, porém, deter-nos-emos na descrição da análise das Diretrizes Curriculares Nacionais dos cursos superiores destacados nas dissertações e teses em apreço neste trabalho, desenvolvida a partir das referências teóricas da Aprendizagem Significativa.

\section{Educação Superior e Diretrizes Curriculares Nacionais para os cursos destacados nos trabalhos analisados}

Na sequência, apresentamos a análise a que submetemos as Diretrizes Curriculares Nacionais (DCNs) dos cursos de Matemática e Física, tidos em maior destaque nas dissertações e teses selecionadas, segundo os princípios teóricos de Ausubel, sobretudo no tocante às habilidades/competências a serem desenvolvidas no decorrer dos cursos pelos acadêmicos e às indicações sobre a aprendizagem constantes no perfil do egresso. 
O Parecer CNE $\mathrm{n}^{\circ}$ 1.302/2001 (Diretrizes Curriculares Nacionais para o curso de Matemática), no item 2, destaca, entre outras competências e habilidades, que o egresso deve estar apto para a identificação e resolução de problemas na sua área de aplicação a partir dos conhecimentos matemáticos que incidem sobre a área (BRASIL, 2001a). Nessa consideração, pode se dizer que os aportes da Teoria de Aprendizagem Significativa são contributivos para a formação do perfil do egresso, dado que essa prerrogativa compreende as atividades profissionais como um meio de produção do conhecimento.

Nesse processo, podemos levar em conta que, ao mesmo tempo em que está progressivamente diferenciando sua estrutura cognitiva, o acadêmico constitui a reconciliação integradora, de modo a identificar semelhanças e diferenças e reorganizar seu conhecimento. É nesse sentido que, para Ausubel (1982, 2006), os princípios da aprendizagem significativa levam o estudante ao pensamento reflexivo. Suspeita-se, no entanto, tratar-se de pensamento crítico emancipador.

Nessa mesma perspectiva, a Teoria da Aprendizagem Significativa contribui com suas premissas quanto ao desenvolvimento do egresso no que diz respeito à habilidade de identificar, elaborar e sanar problemas em sua área de aplicação com base nos conhecimentos matemáticos propugnados pelas Diretrizes Curriculares Nacionais para o curso de Matemática (BRASIL, 2001a), enfatizando que a aprendizagem significativa ocorre a partir do processo da assimilação (subsunçores) e retenção (ancoragem) do conhecimento em três estágios distintos. Primeiramente, ocorre a retenção seletiva do conteúdo de aprendizagem aos conceitos relevantes existentes na estrutura cognitiva; da interação entre as ideias existentes e as ideias novas surge o produto dessa interação; no terceiro estágio ocorre a fusão dos novos significados emergentes com ideias ancoradas/retidas na memória (AUSUBEL, 2006).

O Parecer CNE $n^{\circ} 1.304 / 2001$ (Diretrizes Curriculares Nacionais para o curso de Física), por seu lado, determina, entre outras competências, que o egresso de Física deve desenvolver a habilidade de: a) "descrever e explicar fenômenos naturais, processos e equipamentos [...] em termos de conceitos, teorias e princípios físicos gerais"; b) "diagnosticar, formular e encaminhar a solução de problemas físicos, experimentais ou teóricos, práticos ou abstratos" (BRASIL, 2001b). Considerando tais competências, pode se dizer que a Teoria da Aprendizagem Significativa oferece subsídios para a organização 
de estratégias de ensino, objetivando potencializá-las, ao sugerir o uso de organizadores prévios como estratégia para mobilizar a estrutura cognitiva do acadêmico e ancorar suas novas aprendizagens, ou quando for constatado que os subsunçores existentes em sua estrutura cognitiva não são satisfatórios e estáveis para desempenhar as funções de ancoragem do novo conhecimento.

Nessa direção, os organizadores prévios também podem servir como ativadores de subsunçores que não estão sendo usados pelo estudante, mas que estão presentes na sua estrutura cognitiva. Os organizadores prévios podem ser apresentados aos alunos por meio da utilização de variadas estratégias de ensino, como por exemplo, sob a forma de textos, filmes, esquemas, desenhos, fotos, perguntas, mapas conceituais, entre outros recursos, permitindo a integração dos novos conceitos aprendidos, tornando mais fácil o relacionamento da nova informação com a estrutura cognitiva já existente (MOREIRA; MASINI, 1982).

Finalmente, importa destacar que as competências/habilidades ressaltadas neste texto, propostas nas DCNs, concretizar-se-ão em decorrência do processo de ensino e aprendizagem. O que as define é a integração entre a teoria e a prática, as estratégias que configurarão a ação docente e a motivação para os estudantes apreenderem. Ao docente cabe a mediação dos processos de ensino envolvendo a aprendizagem, assim como os fundamentos e elementos pertinentes à ação educadora. Do mesmo modo, a aprendizagem significativa contribui com os elementos necessários à compreensão da estrutura cognitiva e às ações do seu envolvimento com a aprendizagem, conferindo apoio às práticas docentes.

O que nos preocupa, todavia, é que as competências e habilidades destacadas e analisadas convivem, entre outras, com a que incumbe às instituições de Ensino Superior formar profissionais graduados - neste caso, em Matemática e Física - para se inserir e atender às demandas da sociedade e do mercado (BRASIL, 2001a, 201b). Justamente duas áreas historicamente envolvidas no desenvolvimento do chamado raciocínio lógicooperacional acrítico. Considerando, então, tais questões somadas à sobrevalorização do cognitivo presente no modelo teórico de Ausubel (1982, 2006), interrogamos: a aprendizagem produzida a partir de seus pressupostos será significativa para quem? A quem beneficiará? 


\section{Contexto da pesquisa: considerações sobre a metodologia}

Para estudar a Teoria da Aprendizagem Significativa e sua aplicabilidade na Educação Superior e, assim, responder à questão central do estudo alvo deste trabalho, entendemos, pelos aportes de Bogdan e Biklen (1994), que a pesquisa qualitativa de cunho bibliográfico seria a estratégia para alcançar o resultado esperado, considerando os seguintes critérios, dentre outros: ser descritiva, preocupar-se com o processo (não somente com o resultado), analisar intuitivamente os dados e enfatizar os significados presentes no material bibliográfico selecionado.

Para a obtenção dos dados foi realizada, primeiramente, a busca no Banco de Teses da CAPES e na BDTD pelas dissertações e teses produzidas no período de 2001 a 2014. Tal delimitação deveu-se à disponibilização das dissertações e teses no site da CAPES, na oportunidade do acesso, que serviram de base para a busca dos documentos no banco de dados da BDTD. Nesse propósito utilizamos, primeiramente, dois descritores: "ensino superior" e "aprendizagem significativa", os quais favoreceram acesso a 189 trabalhos (140 dissertações e 49 teses). No refinamento, tomando como referência os descritores mencionados acrescidos do termo "David Ausubel", esse número decresceu para sete trabalhos identificados - Quadro 2, abaixo - como pertencentes à área das Ciências Exatas e da Terra (conforme classificação de saberes do MEC), que nos possibilitaram verificar, quantitativamente, o que havia sido produzido sobre a concepção de Aprendizagem Significativa de Ausubel (1982, 2006) e analisar qualitativamente os dados contidos no material acessado.

Quadro 2: Relação das Teses e Dissertações sobre Aprendizagem Significativa no Ensino Superior analisadas

\begin{tabular}{|l|l|l|l|l|l|}
\hline $\mathbf{N}^{\circ}$ & \multicolumn{1}{|c|}{ TíTULO/AUTOR } & TIPO & ANO & IES & REPOSITÓRIO \\
\hline 1 & $\begin{array}{l}\text { A aprendizagem de algoritmos: } \\
\text { uma experiência no curso de } \\
\text { Tecnologia em Informática do } \\
\text { CEFET-PA } \\
\text { Adelmar Aviz Junior }\end{array}$ & $\begin{array}{l}\text { Dissertação } \\
2007\end{array}$ & $\begin{array}{l}\text { Universidade } \\
\text { Federal do Pará }\end{array}$ & BDTD \\
\hline 2 & $\begin{array}{l}\text { Implementação de uma } \\
\text { proposta de ensino para a } \\
\text { disciplina de Estrutura da }\end{array}$ & Tese & 2009 & $\begin{array}{l}\text { Universidade } \\
\text { Federal do Rio }\end{array}$ & BDTD \\
\hline
\end{tabular}




\begin{tabular}{|c|c|c|c|c|c|}
\hline & $\begin{array}{l}\text { Matéria baseada na teoria dos } \\
\text { campos conceituais de } \\
\text { Vergnaud } \\
\text { Izabel Krey }\end{array}$ & & & Grande do Sul & \\
\hline 3 & $\begin{array}{l}\text { A utilização de jogos concretos n } \\
\text { a aprendizagem de indução } \\
\text { finita no ensino superior } \\
\text { Rafael Jose Alves do Rego } \\
\text { Barros }\end{array}$ & Dissertação & 2011 & $\begin{array}{l}\text { Universidade } \\
\text { Federal Rural } \\
\text { de Pernambuco }\end{array}$ & $\begin{array}{l}\text { BDTD/ } \\
\text { CAPES }\end{array}$ \\
\hline 4 & $\begin{array}{l}\text { Aprendizagem significativa, } \\
\text { explorando alguns conceitos da } \\
\text { geometria analítica: pontos e } \\
\text { retas } \\
\text { Warley Machado Correia }\end{array}$ & Dissertação & 2011 & $\begin{array}{l}\text { Universidade } \\
\text { Federal de } \\
\text { Ouro Preto }\end{array}$ & CAPES \\
\hline 5 & $\begin{array}{l}\text { Desenvolvimento da análise da } \\
\text { vizinhança em mapas } \\
\text { conceituais a partir do uso de } \\
\text { um conceito obrigatório } \\
\text { Camila Aparecida Cicuito }\end{array}$ & Dissertação & 2011 & $\begin{array}{l}\text { Universidade } \\
\text { de São Paulo }\end{array}$ & BDTD \\
\hline 6 & $\begin{array}{l}\text { Uma proposta didática para o } \\
\text { ensino de mecânica quântica nas } \\
\text { licenciaturas: a notação de Dirac } \\
\text { Marina Valentim Barros }\end{array}$ & Dissertação & 2011 & $\begin{array}{l}\text { Universidade } \\
\text { Católica de } \\
\text { Minas Gerais }\end{array}$ & CAPES \\
\hline 7 & $\begin{array}{l}\text { Aprendizagem significativa na } \\
\text { linguagem da Física em um } \\
\text { curso de introdução à Mecânica } \\
\text { Clássica no ensino superior } \\
\text { César Ballestero }\end{array}$ & Tese & 2014 & $\begin{array}{l}\text { Universidade } \\
\text { Estadual do } \\
\text { Paraná }\end{array}$ & BDTD \\
\hline
\end{tabular}

Fonte: elaboração dos autores (2018).

Concluído o processo de busca e seleção das teses e dissertações produzidas no período citado, o encaminhamento subsequente foi definir as categorias de análise e proceder à leitura dos trabalhos, que nos permitiram responder ao problema do estudo em questão: qual a justificativa dos autores das teses e dissertações selecionadas para a opção pela Teoria da Aprendizagem de Ausubel na Educação Superior?

$\mathrm{Na}$ análise das produções, foi possível identificar as seguintes categorias: justificativa da opção pela teoria de Ausubel, situação da aplicação da teoria e 
resultado/conclusões. No tocante à justificativa pela teoria de Ausubel, consideramos as principais razões apresentadas no trabalho em relação à escolha pela teoria em questão. A situação da aplicação da Teoria da Aprendizagem Significativa refere-se à forma como a teoria foi aplicada: se como referencial teórico para análise e/ou como referencial para aplicação de sequência didática. A categoria conclusões/ resultados engloba a síntese conclusiva a que chegaram os autores dos trabalhos analisados.

Faz-se necessário salientar o fato de que as produções acadêmicas analisadas advêm de distintas áreas geográficas brasileiras. O Sudeste (São Paulo e Minas Gerais) apresenta maior número de produções, com três no total; do Sul (Paraná e Rio Grande do Sul), foram selecionadas duas produções; do Nordeste (Pernambuco), uma produção; e da região Norte (Pará), igualmente uma produção.

As sete produções consideradas para análise caracterizam-se como pesquisas de cunho qualitativo-diagnóstico a partir da aplicação didático-metodológica da Teoria da Aprendizagem Significativa. Pode-se dizer que estudos dessa natureza se constituem inspirados no modelo de pesquisa experimental, tendo em vista compreender análise $a$ priori; aplicação (experimentação) e análise a posteriori (Mello, 1999).

\section{Aprendizagem Significativa nas dissertações e teses brasileiras}

No que tange à justificativa da opção pela Teoria da Aprendizagem Significativa nas produções em apreço, identificamos que a totalidade dos autores explicou a opção pela Teoria da Aprendizagem de Ausubel em razão de seus pressupostos oportunizarem a reflexão da prática pedagógica. Além disso, cinco trabalhos apontaram que a opção foi também devido ao fato de que tal teoria, como fundamento didático, facilita a aprendizagem dos alunos, em vista de que, como destaca o T3 de Barros, R (2011), uma de suas premissas teóricas constitui-se no argumento de "que o conteúdo a ser ensinado faça sentido para o aprendiz" (p.23), que terá mais chances de acontecer se os saberes prévios deste forem considerados na aprendizagem de novos conceitos. Outros dois trabalhos acrescentaram à sua justificativa a indicação do mapa conceitual como potencializador de significados. 
Como nos referimos, os autores das produções aqui consideradas indicaram, por unanimidade, que a teoria de Ausubel, por seus fundamentos, possibilita ao professor refletir sobre sua prática docente. Para ilustrar essa constatação, valemo-nos da declaração da autora do $\mathrm{T}^{2}$, que diz ter optado pela teoria em questão por favorecer enfocar a "disciplina de forma diferenciada, da que é usualmente utilizada, a partir de situações baseadas [...] na Teoria da Aprendizagem Significativa de David Ausubel." (KREY, 2009). Considerando que faz referência à disciplina de um curso de formação de professores, complementa justificando que, dessa forma, os futuros professores seriam "preparados a trabalhar os conteúdos da Física Moderna no ensino médio através de uma aprendizagem significativa" (KREY, 2002, p. 10).

A concepção de que a teoria de Ausubel, como fundamento didático, facilita a aprendizagem dos alunos, apareceu em cinco dos sete trabalhos analisados. Esses direcionam os conceitos à compreensão do processo de ensino-aprendizagem, à reflexão da prática, como fica evidenciado na afirmação do autor do T7:

entendimento de sua teoria contribuiu expressivamente para a compreensão do processo ensino aprendizagem e sobretudo, o do ensino da Física [...] já que os alunos trazem consigo uma bagagem de informações de seu cotidiano que poderia ser aproveitado pelo professor em um processo de ensino de forma a favorecer a aprendizagem significativa. (BALLESTERO, 2014, p. 14)

Para o conjunto dos autores analisados, a justificativa referente à opção pela aprendizagem significativa deve-se ao fato de tomarem os conhecimentos adquiridos pelos estudantes ao longo da vida escolar e acadêmica como referência para a aprendizagem dos chamados conceitos obrigatórios, possibilitando-lhes aprender novos conteúdos de forma significativa e incorporar novos conhecimentos. O autor do T7, ao justificar a opção pela teoria de Ausubel (2006), também resgata seu mais importante princípio, ou seja: "o fator que mais influencia a aprendizagem é aquilo que o aluno já sabe, por isso cabe ao professor identificá-lo e ensinar de acordo" (BALLESTERO, 2014, p. 12). Reafirma, portanto, a posição do autor de que devemos ter conhecimento do que o aluno sabe para a aprendizagem significativa. Isto é, saber avaliar o que o discente

\footnotetext{
${ }^{2} \mathrm{~T}$ corresponde à dissertação/tese analisada e o número, que lhe segue, indica sua ordem no Quadro 2.
} 
aprende é imprescindível no processo de aprendizagem. Ao compreendermos o que apreendeu, conseguiremos definir o que ensinar a ele na sequência do processo docente.

No tocante à aplicação da Teoria da Aprendizagem de Ausubel, identificamos que a totalidade dos autores atribui aos princípios da teoria o fato de favorecer a discussão sobre sua premissa mais importante, que são os conhecimentos prévios. Sete autores discutiram os princípios sobre a formulação de conceitos, enquanto cinco trabalhos apontaram que a aprendizagem significativa tem como foco os processos cognitivos, possibilitando o desenvolvimento e a plasticidade da estrutura cognitiva.

Os sentidos correspondentes à situação da Teoria de Ausubel, que emergiram nos trabalhos investigados, foram tomados por seus autores para a formulação das sequências didáticas aplicadas como chave das pesquisas por eles relatadas. As sequências didáticas são um conjunto de atividades elaboradas etapa por etapa para atingir um objetivo e/ou a necessidade do educando. Os autores analisados, ao descreverem-nas, explicitaram suas etapas, começando pelo levantamento dos conhecimentos prévios utilizados como subsunçores. Em seguida, mencionaram os procedimentos metodológicos utilizados com vistas a considerar os conhecimentos prévios dos alunos, entre eles, mapas conceituais, jogos, esquemas e exercícios para, assim, oportunizar aos estudantes o desenvolvimento da aprendizagem significativa.

Em se tratando dos fatores implicados nos processos cognitivos para a superação da memorização, as produções evidenciam que a memória, para a teoria de Ausubel, a partir de seus nexos conceituais e dos significados preexistentes, pode mobilizar a estrutura cognitiva diante de um novo conceito ou assimilação de uma nova informação. A memória é um recurso cognitivo relacionado ao domínio conceitual, cuja aplicabilidade possui princípios gerais que podem ser utilizados em situações diversas. Contrariamente, a aprendizagem mecânica de novas informações possui pouca ou nenhuma conexão com conceitos existentes na estrutura cognitiva. A memória, para a teoria de Ausubel, tem papel ativador dinâmico no processo da aprendizagem significativa.

Outro fator que reforça as diferentes concepções entre aprendizagem significativa e memória pode ser ilustrado pelas palavras da autora do T6: 
O uso de vetores também fora empregado baseado na proposta de aprendizagem significativa da teoria de Ausubel, permitindo que novo assunto seja construído de maneira significativa. O professor resolveu os exercícios juntamente aos alunos, explicando e retomando a parte teórica, fazendo uso dos conhecimentos prévios detidos pelos alunos para a nova notação. A aula expositiva fez uso do material ancorado na notação vetorial, com participação plena dos alunos por meio de perguntas e observações por ele realizadas, com o intuito de frisar os novos conhecimentos através dos conhecimentos já detidos pelos alunos. (BARROS, M, 2011, p. 30)

Nessa mesma direção, parte-se do princípio de que conhecimentos já memorizados (subsunçores) existentes na estrutura cognitiva, interagindo com novos conceitos, constituem-se em nova organização cognitiva. Os autores demonstram que é essencial e primordial inteirar-se do conhecimento prévio dos alunos para, após as atividades desenvolvidas nas sequências didáticas, avaliar os conhecimentos já adquiridos. Estes, por conseguinte, serão subsunçores para conhecimentos mais complexos, que, segundo Barros, M (2011), são fundamentais para que os alunos, a partir de conhecimentos já adquiridos se apropriem de forma significativa de conhecimentos novos. Segundo a teoria de Ausubel, "tais conteúdos dão a possibilidade de construção de novos conhecimentos para aprender coisas novas de forma significativa para a formação individual do aluno" (AUSUBEL, 2006, p. 79).

É possível percebermos, pelas declarações registradas, que a contribuição de Ausubel (2006), deve-se ao ponto mais importante de sua teoria: a estrutura cognitiva, os conhecimentos prévios do aluno. A estrutura cognitiva pode ser ampliada de duas maneiras: substantivamente (pela inserção de princípios e conceitos integradores com maior poder unificador) ou programaticamente (pelo uso de métodos e sequência didática adequados). Nessa perspectiva, o professor deve diagnosticar o conhecimento prévio do aluno, utilizando princípios e recursos adequados para auxiliá-lo a assimilar e organizar os novos conteúdos em sua estrutura cognitiva.

$\mathrm{Na}$ categoria a seguir, discutimos os sentidos correspondentes aos fatores implicados nos resultados e conclusões descritos nos trabalhos investigados. Nas produções em apreço, quatro dos autores dos trabalhos entenderam que os alunos, ao executarem atividades programadas tendo como fundamento a teoria de Ausubel, apresentaram melhoria na habilidade de formular conceitos, enquanto três deles 
destacaram a importância do trabalho colaborativo para a aprendizagem significativa. Outro autor relata sobre a necessidade de se avaliar e investigar o processo de retenção e assimilação do conhecimento dos discentes para uma aprendizagem significativa, como veremos a seguir.

Os resultados e conclusões das distintas produções evidenciam que a maioria dos autores considera que a melhoria na habilidade de formulação de conceitos entre os participantes das atividades pedagógicas foi devido ao uso de ferramentas adequadas que facilitam a aprendizagem significativa. Representativa, nesse sentido, é a afirmação constante no T2: os dados analisados "apresentaram fortes evidências de que as metodologias adotadas foram aprovadas pelos alunos e na concepção de que a aprendizagem significativa interfere diretamente em selecionar e abordar os conteúdos que trabalhará futuramente nas salas de aula" (KREY, 2009, p. 82). Destacamos, entre os principais procedimentos metodológicos, a aplicação de mapas conceituais, o desenvolvimento de conceitos obrigatórios (CO), a análise da vizinhança (AVIZ), o uso de jogos.

Outro fator, ainda, que reitera a importância do desenvolvimento da aprendizagem significativa nos resultados e conclusões dos trabalhos analisados é o envolvimento coletivo colaborativo por parte dos discentes, conforme expressa o autor do T1:

\begin{abstract}
A ideia de que a disciplina de algoritmos constituía um obstáculo difícil de ser superado foi sobrepujada com a construção do projeto que permitiu um rápido envolvimento constatado pelo estreitamento do relacionamento produtivo e colaborativo que havia entre todos, o que facilitou para a criação de um ótimo ambiente de aprendizagem. (AVIZ JUNIOR, 2007, p. 71)
\end{abstract}

Da mesma forma, o autor do T4 (p. 98) descreve que os discentes, ao realizarem atividades com metodologias que favorecem a aprendizagem significativa, envolvem-se, primeiramente, porque "têm a possibilidade de interagirem, trocando ideias ou fornecendo informações" (CORREIA, 2011, p. 98), depois porque, num segundo momento, a interação "poderá ocorrer na socialização das tarefas, quando os grupos têm a oportunidade de se comunicar verbalmente, emitindo sugestões e tirando dúvidas" (CORREIA, 2011, p. 98). Essa declaração identifica-se com a teoria de Ausubel (2006), 
quando reconhece que a comunicação é fundamental para a construção de significados e nas relações entre as representações simbólicas (verbais, gráficas e conceituais) expostas em sala de aula. A interação em aula facilita aos alunos produzirem seus conhecimentos, constituírem significados e, por fim, estabelecerem relações interpessoais.

No que diz respeito aos fatores relativos à avaliação/investigação dos conhecimentos dos alunos, os autores analisados salientam a importância, por parte do docente, do conhecimento prévio dos estudantes. Ao investigar, avaliar o que estes conhecem, o professor, tendo como base os princípios e os procedimentos metodológicos que orientam a aprendizagem significativa, poderá planejar suas atividades com vistas à utilização desse conhecimento.

Conforme Ausubel (2006), para que ocorra a aprendizagem significativa duas condições são essenciais: o discente deve ter disposição para aprender e o material didático deve ser significativo. Apenas desse modo haverá o entendimento de conceitos e proposições, implicando a apropriação de significados objetivos e intransferíveis. Assim sendo, para que aconteça a avaliação consistente desses conteúdos, o método adequado, para o autor, reside em investigar de várias formas os problemas apresentados, utilizando-se de recursos diversos. Dessa forma, poderá constatar se o aluno desenvolveu, de fato, as habilidades necessárias à aprendizagem significativa.

Por certo, essa foi essa a razão pela qual um dos principais métodos defendidos pelos autores das produções selecionadas tenha sido o dos mapas conceituais, aplicados para avaliar o aprendizado dos alunos e, possivelmente, identificar se tal aprendizado ocorreu de forma significativa (NOVAK, 1981). Nesse sentido, o autor do T5 afirma que

\footnotetext{
mapas conceituais são identificados como instrumentos de aprendizagem significativa que devem ser analisados a partir de procedimentos inovadores, permitindo ao professor que sejam estabelecidas condições mais adequadas de orientação dos alunos diante da superação das estruturas que fizeram parte do processo de ensinoaprendizagem. (CICUITO, 2011, p. 92)
}

Para os autores das dissertações e teses apreciadas, os resultados alcançados na elaboração dos mapas conceituais permitem aos alunos realizar inferências não somente em relação ao significado conceitual, mas também das interpelações entre eles. Essas 
considerações são importantes, pois permitem avaliar se os discentes apreenderam os conceitos de forma correta, descrever as dificuldades encontradas e apontar diferentes modos de abordar o conteúdo em sala de aula.

\section{Considerações finais}

Objetivamos, no estudo realizado, a análise da Teoria da Aprendizagem Significativa no contexto teórico do processo de aprendizagem, verificando como seus princípios orientam sua aplicação no âmbito do ensino superior brasileiro, mediante análise de teses e dissertações brasileiras produzidas no período de 2007 a 2014.

Conforme apontado, as bases teóricas de Ausubel (1982, 2006) na esfera da aprendizagem significativa contrapõem-se aos preceitos das teorias advindas do behaviorismo, de modo que aprender significativamente, na sua concepção, diz respeito à ampliação e reconfiguração das ideias já existentes na estrutura cognitiva do estudante, na relação com novos conhecimentos.

O estudo que desenvolvemos das produções acadêmicas deu-se por meio da análise de sete dissertações e teses selecionadas no período indicado. A busca extensa e sistematizada no banco de dados da CAPES e BDTD permitiu-nos relacionar a metodologia e a opção teórica desenvolvida pelos autores das teses e dissertações, como também acessar os sentidos correspondentes à situação da teoria de Ausubel e aos resultados e conclusões descritos.

Na obtenção da resposta da questão central do estudo, ou seja, a justificativa dos autores dos trabalhos analisados a respeito da opção pela Teoria da Aprendizagem de Ausubel, os resultados apresentados indicam que a teoria em questão oportunizou a reflexão sobre a prática docente. Chama atenção, nesse aspecto, o fato de que todos os autores dos trabalhos investigados consideraram que a Teoria da Aprendizagem Significativa, como fundamento didático, "facilitou" a aprendizagem dos alunos, favorecida pela aplicação dos mapas conceituais como potencializadores de significados e imprescindíveis ao processo de aprendizagem.

Percebemos, ainda, que em relação à situação da teoria de Ausubel, a totalidade dos autores dos trabalhos aplicou a sequência didática como metodologia para dar 
resposta à sua questão de investigação. Destacamos, nessa categoria, a presença de três premissas importantes da Teoria da Aprendizagem Significativa: a função dos processos cognitivos, a formulação de conceitos e, por fim, os conhecimentos prévios, princípio fundamental da teoria em questão. O conhecimento e aplicabilidade dessa base conceitual permitiram aos referidos autores, através da metodologia utilizada, verificar se os conhecimentos prévios estariam disponíveis na estrutura cognitiva dos alunos, evidenciando, assim, a ocorrência da aprendizagem significativa.

Os trabalhos, predominantemente, descrevem, em seus resultados e conclusões, a incidência da aprendizagem significativa dos alunos (mesmo em diferentes disciplinas e conteúdos) e maior autonomia destes em relação à aquisição do saber e de novos conhecimentos. O teor genérico desse último aspecto - a autonomia - no entanto, não nos permitiu apreender com clareza o seu significado. Além desses fatores, enfatizam o relacionamento colaborativo (socialização e discussão) e a indispensabilidade do professor como articulador de conhecimentos e informações para que se produza a aprendizagem significativa, fazendo uso de metodologias e de processos de ensino alinhados à teoria em apreço.

Outra questão substancial verificada nas produções analisadas refere-se à importância do planejamento de ensino com objetivos definidos, tendo a avaliação diagnóstica dos conhecimentos prévios dos alunos como base para a formulação das estratégias de ensino.

O problema reside, no entanto, na utilização da sequência didática como metodologia de pesquisa. Muitos pesquisadores consideram sua descrição e análise como relato de experiência. Assim, no decorrer deste trabalho, surgiram indagações, entre as quais: a descrição/análise de sequência didática cumpre o papel de pesquisa científica? Talvez uma possibilidade de responder a esse questionamento seja ampliar o estudo no contexto das instituições de ensino superior, especialmente nos espaços em que se dá a prática docente.

Finalmente, esperamos que este estudo possa servir como referencial para que futuras pesquisas sejam realizadas, buscando aprofundar outros aspectos no tocante às teorias de aprendizagem em caráter geral e à Teoria da Aprendizagem Significativa em específico. Pesquisas que proporcionem verificar como as outras teorias impactam 
diretamente nos resultados da opção teórica pela aprendizagem significativa, bem como os modos por meio dos quais se dá a concepção desta em outros níveis de escolaridade e a partir do ensino de outras disciplinas voltadas à concepção fundamental da aprendizagem significativa.

\section{Referências}

AUSUBEL, David Paul. A aprendizagem significativa: a teoria de David Ausubel. São Paulo: Moraes, 1982.

AUSUBEL, David Paul. Aquisição e retenção de conhecimentos: uma perspectiva cognitiva. Lisboa: Plátano, 2006.

AUSUBEL, David Paul; NOVAK, Joseph. Donald; HANESIAN, Helen. Psicologia educacional. Rio de Janeiro: Interamericana, 1980.

AVIZ JUNIOR, Adelmar Alves. A aprendizagem de algoritmos: uma experiência no curso de Tecnologia em Informática do CEFET-PA. 2007. Dissertação (Mestrado Educação em Ciências e Matemática) - Universidade Federal do Pará, Programa de Pós-Graduação em Educação em Ciências e Matemáticas, Núcleo Pedagógico de Apoio ao Desenvolvimento Científico, Belém, 2007.

BALLESTERO, Henrique Cesar Estevan. Aprendizagem significativa da linguagem física em um curso de introdução à mecânica clássica no ensino superior. 2014. Tese (Doutorado em Ensino de Ciências e Educação Matemática) - Universidade Estadual de Londrina, Londrina, 2014.

BARROS, Marina Valentim. Uma proposta didática para o ensino de mecânica quântica nas licenciaturas: a notação de Dirac. 2011. Dissertação (Mestrado Profissional em Ensino) - Pontifícia Universidade Católica de Minas Gerais, Belo Horizonte, 2011.

BARROS, Rafael Jose Alves do Rego. A utilização de jogos concretos na aprendizagem de indução finita no ensino superior. 2011. Dissertação (Mestrado em Ensino das Ciências) Universidade Federal Rural de Pernambuco, Recife, 2011.

BOGDAN, Robert Charterhouse; BIKLEN, Sari Knopp. Investigação qualitativa em educação. Porto: Porto, 1994.

BRASIL. Parecer CNE n 1.302/2001. Brasília, DF: CNE/MEC, 2001a. Disponível em: portal.mec.gov.br/cne/arquivos/pdf/CES13022.pdf. Acesso em: set. 2018. 
BRASIL. Parecer CNE n 1.304/2001. Brasília, DF: CNE/MEC, 2001b. Disponível em: http://portal.mec.gov.br/cne/arquivos/pdf/CES1304.pdf. Acesso em: 18 set. 2018.

CACHAPUZ, Antonio Francisco. A procura da excelência na aprendizagem. Série-Estudos, Campo Grande, n. 10, p. 9-26, dez. 2000. Disponível em: http://www.serie-

estudos.ucdb.br/index.php/serie-estudos/article/view/596/484. Acesso em: 20 jul. 2017.

CICUITO, Camila Aparecida Tolentino. Desenvolvimento da análise de vizinhança em mapas conceituais a partir de uso de um conceito obrigatório. 2011. Dissertação (Mestrado em Ensino de Química) - Universidade de São Paulo, São Paulo, 2011. Disponível em: Camila_Aparecida_Tolentino_Cicuto.pdf. Acesso em: 26 jun. 2018.

CORREIA, Warley Machado. Aprendizagem significativa, explorando alguns conceitos de geometria analítica: pontos e retas. Dissertação (Mestrado em Educação Matemática) Universidade Federal de Ouro Preto, Minas gerais, 2011.

GALAGOVSKY, Lydia Raquel. Del aprendizaje significativo al aprendizaje sustentable. Parte 1: el modelo teórico. Enseñanza de la Ciencias, Barcelona, v. 22, n. 2, p. 229-240, 2004.

KLEINKE, Rita de Cássia Marques. Aprendizagem significativa: pedagogia por projetos no processo de alfabetização. 2003. (Mestrado em Engenharia de Produção) Universidade Federal de Santa Catarina, Florianópolis, 2003.

KREY, ISABEL. Implementação de uma proposta de ensino para a disciplina de Estrutura da Matéria Baseada na Teoria dos Campos Conceituais de Vergnaud. 2009. Tese. (Doutorado em Física) - Universidade Federal do Rio Grande do Sul, Porto Alegre, 2009.

MACHADO, Marta de Azevedo. O ensino de física térmica na perspectiva da aprendizagem significativa: uma aplicação no ensino médio. 2015. Dissertação (Mestrado Profissional em Ensino de Ciências - Física) - Universidade Federal de Ouro Preto, Ouro Preto, 2015.

MELLO, Elizabeth G. S. Demonstração: uma sequência didática para a introdução de seu aprendizado no ensino da geometria. 1999. Dissertação (Mestrado em Educação Matemática, Pontifícia Universidade Católica de São Paulo, São Paulo, 1999.

MOREIRA, Marco Antônio. Aprendizagem significativa. Brasília: Editora Universidade de Brasília, 1999.

MOREIRA, Marco Antônio. Mapas conceituais e aprendizagem significativa. São Paulo: Centauro Editora. 2010.

MOREIRA, Marco Antônio. Aprendizagem significativa: a teoria e textos complementares. Ed. da Física. São Paulo. 2012. 
MOREIRA, Marco Antônio. Aprendizagem significativa: uma ilusão perdida em uma cultura de ensino para a testagem? In: ENCONTRO INTERNACIONAL SOBRE APRENDIZAGEM SIGNIFICATIVA, 6., 2015, Burgos. Anais [...]. Burgos, Espanha: [s.n], jul. 2015. p. 1-11. Conferência de encerramento. Disponível em: https://ri.ufs.br/bitstream/ riufs/9319/4/Aprendizagem_significativa_uma_ilus\%C3\%A30_perdida_em_cultura.pdf. Acesso em: 09 abr. 2019.

MOREIRA Marco. Antônio; MASINI Elcie F. Salzano. Aprendizagem significativa: a teoria de David Ausubel. São Paulo: Moraes, 1982.NOVAK, Joseph Donald. Uma teoria de educação. São Paulo: Pioneira, 1981.

PELIZZARI, Adriana et al. Teoria da aprendizagem significativa segundo Ausubel. Educação, Revista PEC, Curitiba, v. 2, n. 1, p. 39-42, jul. 2001.

PÉREZ GÓMEZ, Ángel Ignacio. Os processos de ensino-aprendizagem: análise didática das principais teorias de aprendizagem. In: SACRISTÁN, Gimeno José; PÉREZ GÓMEZ, Ángel Ignácio. Compreender e transformar ensino. Porto Alegre: Artmed, 1998.

PIVATTO, Brum; SCHUHMACHER, Elcio. Conceitos de teoria da aprendizagem significativa sob a ótica dos mapas conceituais a partir do ensino de geometria. REVEMAT, Florianópolis, v. 8, n. 2, p. 194-221, 2013.

STUDER, CAREN Elizabeth; CASAGRANDE, Lisete Diniz Ribas. Aprendizagem significativa: relato de experiência no ensino superior. Paidéia, Ribeirão Preto: FFCLRP-USP, dez. 1999.

VALADARES, Jorge; MOREIRA, Marco Antônio. A teoria da aprendizagem significativa: sua fundamentação e implementação. Coimbra: Almedina, 2009.

Recebido em: 19/12/2018 Revisões requeridas: 25/03/2019 Aprovado em: 02/05/2029

Universidade do Estado de Santa Catarina - UDESC Programa de Pós-Graduação em Educação - PPGE Revista Linhas Volume 21 - Número 46 - Ano 2020 revistalinhas@gmail.com 